\title{
Association of Cognitive Dysfunction with Cardiovascular Autonomic Nerve Abnormalities in Early Parkinson Disease
}

\author{
Liu-Qian ${ }^{1 *}$, Cao-Hui ${ }^{2 *}$, Chen-Hudan ${ }^{3 *}$, Xu-Jianfeng ${ }^{2}$, Huang-Jun ${ }^{1}$, Sun-Hanlin ${ }^{1}$, Li-Mengqiiu ${ }^{1}$ and Lai-Yujie ${ }^{4 *}$ \\ ${ }^{1}$ Department of Neurology, The Third Hospital of Mianyang, Sichuan Mental Health Center, China
}

${ }^{2}$ Department of Neurosurgery, The Third Hospital of Mianyang, Sichuan Mental Health Center, China

${ }^{3}$ Department of Psychiatry, The Third Hospital of Mianyang, Sichuan Mental Health Center, China

${ }^{4}$ Department of Neurology, The Third Affiliated Hospital of Chongqing Medical University (Gener Hospital), China

Submission: June 07, 2021; Published: June 15, 2021

*Corresponding author: Lai-Yujie, Department of Neurology, The Third Affiliated Hospital of Chongqing Medical University (Gener Hospital), China

\section{Abstract} pateints.

Methods: 78 newly diagnosed patients with PD were recruited from the third hospital of Mianyang from June 1,2016 to December 31, 2019. All participants underwent physical examinations and auxiliary examinations, including electrocardiogram, echocardiography. Neuropsychological scales were used to evaluate their global cognitive function, memory function, fluency, executive function and processing speed. The association between cardiovascular autonomic nerve abnormalities and cognitive funotion via linear regression analysis was assessed.

Results: The cognition impairment group showed poorer performances on MMSE $(<0.001)$, MoCA-B $(<0.001)$, episodic memory $(\mathrm{P}<0.05$ ), language $(<0.001)$, and executive function $(\mathrm{P}<0.05)$ than the normal cognition group. No significant difference was observed in the scores of information prosessing speed ( $\mathrm{P}>0.05$ ). Linear regression analysis was conducted with systolic blood pressure, diastolic blood pressure, RMSSD, pNN50\% as independent variables and cognitive function score as dependent variables. The score of N5 in episodic memory linearly related to RMSSD $(\mathrm{P}<0.05)$. There was no significant linear relationship between the general cognition and the various cognitive domains and HRV. Conclusion: cardiovascular autonomic nerve abnormalities may play an important role in PDD pathogenesis, and improving cardiovascular autonomic nerve abnormalities might be helpful for the prevention of PDD.

Keywords: Cognition; Neuropsychological tests; Parkinson's disease; Cardiovascular autonomic nerve abnormalities

\section{Introduction}

Parkinson disease (PD) is a movement disorder that affects about $1 \%-2 \%$ of individuals older than 60 years and is characterised by cardinal motor manifestations of rigidity, bradykinesia, postural instability and tremor [1-6,7-9,10-22]. In addition to these motor symptoms, many patients suffer from a wide range of nonmotor symptoms that sometimes even precede the typical movement disorder, such as dementia, gastroparesis, sleep disturbances (i.e. rapid eye movement sleep behavior disorder), depression, constipation, and other dysautonomic symptoms [2]. Dementia is one of the most prevalent nonmotor symptoms in PD patients (PDD), with the prevalence and annual incidence are estimated at respectively $30-40 \%$ and $10 \%$ of
PD patients [16]. Previous studies suggested that cognitive dysfunction occur in the later course of disease [11]. However, recent researches found that patients with PD are susceptible to cognitive dysfunction, even early in the disease [13]. This indicates that such potentially disabling nonmotor symptoms of PD should be carefully addressed in clinical management.

However, the exact pathogenesis of PDD is still unknown; Some vascular risk factors and/or neurocirculatory abnormalities have been noted in PDD $[14,15]$. Previous studies suggested that vascular risk factors were significantly associated with cognitive in patients with early PD [18,21]. Cardiovascular symptoms are common causes of PD patients' medical treatment26. PD 
patients with cardiovascular autonomic dysfunction will cause falls, syncope and other adverse conditions, increase the risk of cardiovascular and cerebrovascular diseases. In the past, it was thought that cardiovascular autonomic nerve dysfunction only occurred in the late stage of $\mathrm{PD}$, but now it is found that cardiovascular autonomic nerve dysfunction is also common in PD patients who do not use drugs in the early stage $[3,19]$. Epidemiological studies have also revealed PDD may be related to orthostatic hypotension [1], supine hypertension, labile blood pressure [20], and the absence of a decrease in pressure during night [23]. Although studies reported different findings, these findings still seem to imply that cardiovascular autonomic nerve abnormalities may play a crucial role in PDD pathogenesis.

Heart rate variability (HRV) has attracted more and more attention in the assessment of cardiovascular autonomic nervous function in patients which have been widely used in diabetes and cardiovascular disease patients. However, the relationship among HRV and PDD remains unknown. In the present study, we assessed whether cognitive abnormalities in early PD stage were related to $\mathrm{HRV}$.

\section{Materials and Methods}

\section{Diagnosis and Clinical Evaluation of PD}

78 newly diagnosed patients with PD were recruited from the third hospital of Mianyang from June 1, 2016 to December 31, 2019. A clinical diagnosis of early PD was made according to the UK Brain Bank criteria [7]. None of the patients had ever taken medication for PD. We collected demographic data (age, gender and education level), medical history and clinical details (age at onset and disease duration). Disease severity was evaluated by Hoehn \& Yahr stage and motor disability was assessed with the Movement Disorders Society-revised Unified Parkinson's Disease Rating Scale (MDS-UPDRS) parts III8. Lacunae and white matter lesions were evaluated using a previously recommended standard $[24,25]$. All MRI scans were performed on a 3.0 Tesla Magnetom Skyra MRI scanner (Siemens Medical Solutions, Erlangen, Germany) [26].

Excluded from the study were patients with: (1) neurological abnormalities related to atypical and secondary Parkinsonism; (2) current intake of medications known to influence autonomic functions; (3) multiple system atrophy; (4) corticobasal degeneration; (5) a history of cardiopathy or peripheral neuropathy [17].

\section{Echocardiography}

All participants underwentphysical examinations and auxiliary examinations, including electrocardiogram, echocardiography. The left ventricle ejection fraction, left ventricular internal dimension (LVID) and left ventricular posterior wall thickness (LVPWT) were obtained from echocardiography measurements.

\section{Neuropsychological Measurement}

All subjects underwent a standardized neuropsychological measurement protocol performed by an experienced neuropsychologist. Global cognitive function was assessed using the MMSE and Montreal Cognitive Assessment (MoCA-B). In addition, a neuropsychological battery that included AVLT-N5/ N7, Category Verbal Fluency (CVF), Boston Naming Test (BNT), Trail Making Test-A/B was used to evaluate the multiple cognitive domains of episodic memory, language, executive function, and information processing speed.

\section{Detection of Holter and Analysis of HRV}

All patients were recorded 24-hour heart rate dynamic changes by synchronous 12 lead dynamic electrocardiograph, and analyzed HRV time domain. Time domain indicators include: standard deviation of normal RR intervals (SDNN), root mean square successive difference of normal RR invervals (RMSSD), percentage of adjacent R-R intervals that varied by more than 50ms (PNN50\%), and standard deviation NN average(SDANN).

\section{Data Analysis and Statistics}

Continuous and normally distributed variables were expressed as mean \pm standard deviation (SD) , and variables not normally distribution were expressed as median (IQR). Categorical data were described using frequency and percentages. The differences in the demographic data between the two groups were assessed by an independent $\mathrm{t}$ test, $\mathrm{x} 2$ test, Mann-Whitney $\mathrm{U}$ test, or Chisquared test. Multivariate logistic regression was used to identify the factors associated with MMSE scores. All hypothesis tests were two-tailed, and $\mathrm{p}<0.05$ was defined as statistically significant. Statistical analyses were performed using SPSS version 21.0.

\section{Result}

\section{Demographic Characteristics}

Among the patients, 39 were men and 39 were women. Mean age $( \pm \mathrm{SD})$ was $65.87 \pm 7.85$ years and motor symptoms duration was $1.76 \pm 0.99$ years. UPDRS scores averaged $19.94 \pm 11.98$ and H\&Y stage scores averaged $1.63 \pm 1.12$. The patients therefore had relatively mild PD of short duration. Thirty-one patients had normal cognition, forty-seven had cognitive impairment. No differences in age, gender, education, smoking history, hyperlipidemia, diabetes mellitus, hypertention, lacunae, or WMC were found between the two groups ( $\mathrm{P}>0.05$ ) (Table 1$)$. Mean systolic and diastolic blood pressure was higher in the cognitive impairment group $(\mathrm{P}<0.05$ ). There was no significant difference in the cognitive impairment group by both UPDRS and H \&Y stages.

\section{Cognition Impairment}

The cognition impairment group showed poorer performances on $\operatorname{MMSE}(<0.001)$, MoCA-B $<0.001)$, episodic memory $(\mathrm{P}<0.05$ 
), language $(<0.001)$, and executive function $(\mathrm{P}<0.05)$ than the normal cognition group. No significant difference was observed in the scores of information prosessing speed ( $\mathrm{P}>0.05$ ) (Table 2).

\section{Correlations between HRV and Cognition}

Linear regression analysis was conducted with systolic blood pressure, diastolic blood pressure, RMSSD, pNN50\% as independent variables and cognitive function score as dependent variables. The linear regression results of systolic blood pressure, diastolic blood pressure, RMSSD, pNN50\% with the general cognition and the various cognitive domains are shown in the Table 3. We found the score of N5 in episodic memory linearly related to RMSSD. There was no significant linear relationship between the general cognition and the various cognitive domains and HRV.

Table1: Characteristics of patients in normal cognition and impairmental cognition groups.

\begin{tabular}{|c|c|c|c|c|}
\hline & Normal Cognition $(\mathrm{N}=31)$ & $\begin{array}{l}\text { Cognition Impairment } \\
\qquad(\mathrm{N}=47)\end{array}$ & $T / Z$ Value & $P$ Value \\
\hline Age, $y$, mean $\pm S D$ & $64.68 \pm 8.13$ & $66.66 \pm 7.645$ & -1.093 & 0.278 \\
\hline Men, n(\%) & $17(54.8)$ & $22(46.8)$ & 0.482 & 0.488 \\
\hline Handedness(right/left) & $29 / 2$ & $44 / 3$ & 0.000 & 0.990 \\
\hline Education duration, y, $\left[\mathrm{M}\left(\mathrm{Q}_{25}, \mathrm{Q}_{75}\right)\right]$ & $9.00(9.00,16.00)$ & $9.00(6.00,12.00)$ & -1.447 & 0.148 \\
\hline Disease duration, $\mathrm{y}$, $\left[\mathrm{M}\left(\mathrm{Q}_{25}, \mathrm{Q}_{75}\right)\right]$ & $1.50(1.00,2.10)$ & $1.40(0.90,2.50)$ & -0.788 & 0.431 \\
\hline Hypertention, $\mathrm{n}(\%)$ & $7(22.6)$ & $17(36.2)$ & 1.784 & 0.182 \\
\hline Systolic BP (supine), mm Hg, mean \pm SD & $124.39 \pm 20.80$ & $137.11 \pm 18.26$ & -2.848 & $0.006^{*}$ \\
\hline Diastolic BP (supine), mm Hg, mean \pm SD & $77.81 \pm 13.25$ & $86.81 \pm 15.50$ & -2.655 & $0.010^{*}$ \\
\hline Diabetes mellitus, $\mathrm{n}(\%)$ & $8(25.8)$ & $15(31.9)$ & 0.335 & 0.563 \\
\hline \multicolumn{5}{|l|}{ Smoking status, n(\%) } \\
\hline Nonsmoker & $21(67.7)$ & $34(72.3)$ & 0.190 & 0.663 \\
\hline Ex-smoker & $2(6.5)$ & $5(10.6)$ & 0.401 & 0.527 \\
\hline Current smoker & $8(25.8)$ & $8(17.0)$ & 0.884 & 0.347 \\
\hline H\&Y stage, $\left[M\left(Q_{25}, Q_{75}\right)\right]$ & $1.50(1.00,2.50)$ & $1.50(1.00,2.50)$ & -0.940 & 0.925 \\
\hline UPDRS score, mean \pm SD & $19.42 \pm 12.285$ & $20.30 \pm 11.911$ & -0.315 & 0.754 \\
\hline \multicolumn{5}{|l|}{ Lipid profile, mean \pm SD } \\
\hline Total cholesterol, mg/dl & $164.32 \pm 51.53$ & $174.87 \pm 49.69$ & -0.904 & 0.369 \\
\hline $\mathrm{TG}\left[\mathrm{M}\left(\mathrm{Q}_{25}, \mathrm{Q}_{75}\right)\right] \mathrm{mmol} / \mathrm{L}$ & $1.63(0.97,2.46)$ & $1.92(1.26,2.33)$ & -1.675 & 0.094 \\
\hline LDL-cholesterol, mg/dl & $101.87 \pm 25.51$ & $110.38 \pm 26.23$ & -1.418 & 0.160 \\
\hline Plasma homocysteine level, $\mu \mathrm{mol} / \mathrm{L}$ & $10.748 \pm 4.17$ & $10.643 \pm 2.96$ & -0.131 & 0.896 \\
\hline $\mathrm{HR}$, mean $\pm \mathrm{SD}$ & $81.23 \pm 9.05$ & $60.13 \pm 9.44$ & 1.697 & 0.094 \\
\hline Ejection fraction, mean $\pm \mathrm{SD}(\%)$ & $63.77 \pm 7.977$ & $56.11 \pm 8.646$ & 0.677 & 0.102 \\
\hline $\operatorname{LVID}(\mathrm{mm})$, mean $\pm \mathrm{SD}$ & $43.52 \pm 2.379$ & $42.83 \pm 3.332$ & 0.991 & 0.325 \\
\hline $\operatorname{LVPWT}(\mathrm{mm})$, mean $\pm \mathrm{SD}$ & $9.41 \pm 1.66$ & $9.50 \pm 1.73$ & -0.224 & 0.825 \\
\hline SDNN, mean \pm SD & $92.52 \pm 16.919$ & $98.15 \pm 15.433$ & -1.518 & 0.133 \\
\hline SDANN, mean \pm SD & $71.84 \pm 15.334$ & $74.74 \pm 15.232$ & -0.822 & 0.413 \\
\hline RMSSD, mean \pm SD & $17.26 \pm 4.858$ & $23.06 \pm 6.800$ & -4.109 & $<0.001^{* *}$ \\
\hline PNN50\%, mean \pm SD & $2.652 \pm 0.9416$ & $4.349 \pm 1.5647$ & -5.420 & $<0.001^{* *}$ \\
\hline Lacunae, $\mathrm{n}(\%)$ & $17(0.55)$ & $19(0.40)$ & 1.561 & 0.211 \\
\hline WMC score, $\left[M\left(Q_{25}, Q_{75}\right)\right]$ & $1.00(0.00,2.00)$ & $1.00(1.00,2.00)$ & -0.049 & 0.961 \\
\hline MMSE, mean \pm SD & $27.03 \pm 2.751$ & $19.74 \pm 5.712$ & 6.606 & $<0.001^{* *}$ \\
\hline
\end{tabular}




\section{Psychology and Behavioral Science International Journal}

Table 2: Measurement of cognitive function of patients.

\begin{tabular}{|c|c|c|c|c|}
\hline Scales & Normal Cognition $(\mathrm{N}=31)$ & Cognition Impairment $(\mathrm{N}=47)$ & $T / Z$ Value & $P$ Value \\
\hline \multicolumn{5}{|l|}{ General cognition } \\
\hline MMSE, mean \pm SD & $27.03 \pm 2.751$ & $19.74 \pm 5.712$ & 6.606 & $<0.001$ \\
\hline MoCA-B, mean \pm SD & $27.65 \pm 2.0442$ & $22.06 \pm 2.959$ & 9.153 & $<0.001$ \\
\hline \multicolumn{5}{|c|}{ Composition of each cognitive domain } \\
\hline \multicolumn{5}{|l|}{ Episodic memory } \\
\hline AVLT-N5, $\left[\mathrm{M}\left(\mathrm{Q}_{25}, \mathrm{Q}_{75}\right)\right]$ & $6.00(5.00,7.00)$ & $5.00(4.00,6.00)$ & -2.595 & 0.009 \\
\hline AVLT-N7, $\left[M\left(Q_{25}, Q_{75}\right)\right]$ & $20.00(18.00,20.00)$ & $18.00(17.00,20.00)$ & -2.334 & 0.020 \\
\hline \multicolumn{5}{|c|}{ Information prosessing speed } \\
\hline TMT-A, s, mean \pm SD & $62.13 \pm 15.207$ & $61.49 \pm 19.125$ & 0.156 & 0.876 \\
\hline \multicolumn{5}{|l|}{ Language } \\
\hline VFT & $15.81 \pm 3.535$ & $11.40 \pm 2.446$ & 6.505 & $<0.001$ \\
\hline $\mathrm{BNT}$, mean $\pm \mathrm{SD}$ & $23.52 \pm 3.811$ & $16.49 \pm 5.583$ & 6.123 & $<0.001$ \\
\hline \multicolumn{5}{|l|}{ Executive Function } \\
\hline TMT-B,s, mean \pm SD & $178.71 \pm 24.215$ & $201.83 \pm 38.750$ & -2.959 & 0.004 \\
\hline
\end{tabular}

Table 3: The association between HRV and cognitive damain in patients.

\begin{tabular}{|c|c|c|c|c|c|c|c|c|}
\hline \multirow[t]{2}{*}{ Scale } & \multicolumn{2}{|c|}{ Systolic BP } & \multicolumn{2}{|c|}{ Diastolic BP } & \multicolumn{2}{|c|}{ RMSSD } & \multicolumn{2}{|c|}{ PNN50\% } \\
\hline & B Value & P Value & B Value & P Value & B Value & P Value & B Value & P Value \\
\hline MMSE & -0.079 & 0.863 & 0.23 & 0.616 & 0.155 & 0.346 & -0.02 & 0.898 \\
\hline MoCA-B & -0.221 & 0.613 & 0.514 & 0.243 & 0.229 & 0.146 & 0.017 & 0.908 \\
\hline AVLT-N5 & -0.205 & 0.642 & 0.226 & 0.61 & 0.338 & $0.037^{*}$ & 0.035 & 0.817 \\
\hline AVLT-N7 & 0.125 & 0.778 & -0.246 & 0.581 & 0.146 & 0.359 & -0.266 & 0.085 \\
\hline TMT-A & -0.796 & 0.075 & 0.953 & 0.053 & 0.064 & 0.684 & 0.049 & 0.746 \\
\hline VFT & -0.161 & 0.727 & 0.037 & 0.935 & -0.025 & 0.879 & -0.086 & 0.587 \\
\hline BNT & 0.242 & 0.587 & -0.403 & 0.367 & 0.151 & 0.343 & -0.189 & 0.216 \\
\hline TMT-B & -0.733 & 0.104 & 0.633 & 0.16 & -0.068 & 0.669 & -0.128 & 0.4 \\
\hline
\end{tabular}

\section{Discussion}

Our findings suggest that cognitive decline is associated with cardiovascular autonomic nerve abnormalities, including mean systolic/diastolic blood pressure, SDNN, RMSSD, PNN50\%, and SDANN. To our knowledge, a positive relationship between HRV and cognitive decline in early Parkinson's disease has not been previously reported. Compared to normal cognition group, dementia group demonstrated lower mean systolic/diastolic blood pressure, but higher BNP values, which reflects vagally mediated cardio function. Such an association was not found with LVID and LVPWT, indexes reflects changes in cardiac structure. Therefore, while dementia PD participants had decreased cardio function compared to normal cognition group, only rhythm but not structure dysfunction was associated with cognition deficits. This suggests that cognitive impairment may be associated with autonomic failure as we know heart rhythm is almost regulated by autonomic nevers [4].

Cognitive impairment was present in PDD group, but the pattern of cognitive impairment was different. PDD had lower MMSE and MoCA-B scores along with cognitive impairment in specific damains in PDD. Previous studies conducted to assess working memory deficits in PD reported that deficits occurred only in recall and not in storage or encoding of information. In a similar line, another studies has shown that patients with PD appear to suffer from reduced memory capacity, especially when the capacity is measured by means of storage- and processing tasks. However, our results are slightly different from those of our study. The possible reasons for the differences may be the different selection of subjects and the different selection of cognitive assessment scales.

Interestingly, except the mean systolic/diastolic blood pressure, we did not find differences in vascular risk factors such as diabetes mellitus, hyperlipidemia, WMC score, and lacunae in brain images between the two groups. It is possible that the cognitive decline in early PD and vascular dementia may not share the same central pathogenetic mechanisms. Epidemiological studies highlight the negative prognostic effect of cardiovascular and cerebrovascular autonomic failure on cardiovascular and cerebrovascular outcomes and overall mortality in all $\alpha$-synucleinopathies including PD [5]. Cardiovascular autonomic regulation has been reported to be impaired in Parkinson's disease [10]. Although it had been well known that PD patients often have symptoms or signs of autonomic failure, pathophysiologic bases 
for these complaints had been mysterious. To our knowledge, there may be at least three pathophysiologic mechanisms underlying. The first is loss of cardiac sympathetic noradrenergic nerves. Cardiac sympathetic denervation occurs virtually universally in PD, even in early stage, in a manner that seems surprisingly independent of the movement disorder in individual patients. The second is extra-cardiac noradrenergic denervation. For unknown reasons, loss of extra-cardiac noradrenergic innervation in PD is less extensive than is loss of cardiac innervation. The third determinant is arterial baroreflex failure which changes the blood flow velocities and resistance index of cerebrovessels [12]. In this regard PDD differs from Alzheimer's disease, in which cardiac sympathetic innervation is thought to be generally intact.

In conclusion, cardiovascular autonomic nerve abnormalities may play an important role in PDD pathogenesis, and improving cardiovascular autonomic nerve abnormalities might be helpful for the prevention of PDD. However, association does not imply causation. We speculate from our results that autonomic dysfunction may the original cause of cardiovascular reduced which unavoidable resulted in dementia. Therefore, the relationship between cardiovascular autonomic nerve abnormalities and PDD needs to be further studied in the future.

\section{Fund Program: 17PJ089 and cstc2018jcyjA0166.}

\section{References}

1. Siranan K, Siripan P, Supakit W, Chuthamanee S, Roongroj B, et al (2018) Symptomatic orthostatic hypotension in Parkinson's disease patients: Prevalence, associated factors and its impact on balance confidence. J Neurol Sci 385: 168-174.

2. Antony PM, Diederich NJ, Kruger R, Balling R (2013) The hallmarks of Parkinson's disease. FEBS J 280(23): 5981-5993.

3. Asahina M, Vichayanrat E, Low DA, Iodice V, Mathias CJ, et al. (2013) Autonomic dysfunction in parkinsonian disorders: assessment and pathophysiology. J Neurol Neurosurg Psychiatry 84(6): 674-680.

4. Chen MH, Lu CH, Chen PC, Tsai NW, Huang CC, et al. (2016) Association between autonomic impairment and structural deficit in parkinson disease. Medicine (Baltimore) 95(11): e3086.

5. Fanciulli A, Strano S, Colosimo C, Caltagirone C, Spalletta G, et al. (2013) The potential prognostic role of cardiovascular autonomic failure in alpha-synucleinopathies. Eur J Neurol 20(2): 231-235.

6. Gelb DJ, Oliver E, Gilman S (1999) Diagnostic criteria for Parkinson disease. Arch Neurol 56(1): 33-39.

7. Gibb WR, Lees AJ (1988) The relevance of the Lewy body to the pathogenesis of idiopathic Parkinson's disease. J Neurol Neurosurg Psychiatry 51(6): 745-752.

8. Goetz CG, Tilley BC, Shaftman SR, Stebbins GT, Fahn S, et al. (2008) Movement Disorder Society-sponsored revision of the Unified Parkinson's Disease Rating Scale (MDS-UPDRS): scale presentation and clinimetric testing results. Mov Disord 23(15): 2129-2170.

9. Grunewald A, Kumar KR, Sue CM (2018) New insights into the complex role of mitochondria in Parkinson's disease. Prog Neurobiol.
10. Harnod D, Wen SH, Chen SY, Harnod T (2014) The association of heart rate variability with parkinsonian motor symptom duration. Yonsei Med J 55(5): 1297-1302.

11. Hely MA, Reid WG, Adena MA, Halliday GM, Morris JG, et al. (2008) The Sydney multicenter study of Parkinson's disease: the inevitability of dementia at 20 years. Mov Disord 23(6): 837-844.

12. Jain S, Goldstein DS (2012) Cardiovascular dysautonomia in Parkinson disease: from pathophysiology to pathogenesis. Neurobiol Dis 46(3): 572-580.

13. Kehagia AA, Barker RA, Robbins TW (2010) Neuropsychological and clinical heterogeneity of cognitive impairment and dementia in patients with Parkinson's disease. Lancet Neurol 9(12): 1200-1213.

14. Kim JS, Oh YS, Lee KS, Kim YI, Yang DW, et al. (2012) Association of cognitive dysfunction with neurocirculatory abnormalities in early Parkinson disease. Neurology 79(13): 1323-1331.

15. Kim JS, Oh YS, Lee KS, Song IU, Park IS, et al. (2014) Carotid artery thickening and neurocirculatory abnormalities in de novo Parkinson disease. J Neural Transm (Vienna) 121(10): 1259-1268.

16. Li DTH, Hui ES, Chan Q, Yao N, Chua SE, et al. (2018) Quantitative susceptibility mapping as an indicator of subcortical and limbic iron abnormality in Parkinson's disease with dementia. Neuroimage Clin 20: 365-373.

17. Litvan I, Bhatia KP, Burn DJ, Goetz CG, Lang AE, et al. (2003) Movement Disorders Society Scientific Issues Committee report: SIC Task Force appraisal of clinical diagnostic criteria for Parkinsonian disorders. Mov Disord 18(5): 467-486.

18. Malek N, Lawton MA, Swallow DM, Grosset KA, Marrinan SL, et al. (2016) Vascular disease and vascular risk factors in relation to motor features and cognition in early Parkinson's disease. Mov Disord 31(10): 1518-1526.

19. Muller B, Larsen JP, Wentzel-Larsen T, Skeie GO, Tysnes OB, et al. (2011) Autonomic and sensory symptoms and signs in incident, untreated Parkinson's disease: frequent but mild. Mov Disord 26(1): 65-72.

20. Pathak A, Senard JM (2006) Blood pressure disorders during Parkinson's disease: epidemiology, pathophysiology and management. Expert Rev Neurother 6(8): 1173-1180.

21. Pilotto A, Turrone R, Liepelt-Scarfone I, Bianchi M, Poli L, et al. (2016) Vascular Risk Factors and Cognition in Parkinson's Disease. J Alzheimers Dis 51(2): 563-570.

22. Rugbjerg K, Friis S, Ritz B, Schernhammer ES, Korbo L, et al. (2009) Autoimmune disease and risk for Parkinson disease: a populationbased case-control study. Neurology 73(18): 1462-1468.

23. Sommer S, Aral-Becher B, Jost W (2011) Nondipping in Parkinson's disease. Parkinsons Dis, 897586.

24. Wahlund LO, Barkhof F, Fazekas F, Bronge L, Augustin M, et al. (2001) A new rating scale for age-related white matter changes applicable to MRI and CT. Stroke 32(6): 1318-1322.

25. Wardlaw JM, Smith EE, Biessels GJ, Cordonnier C, Fazekas F, et al. (2013) Neuroimaging standards for research into small vessel disease and its contribution to ageing and neurodegeneration. Lancet Neurol 12(8): 822-838.

26. Willis AW, Schootman M, Kung N, Evanoff BA, Perlmutter JS, et al. (2012) Predictors of survival in patients with Parkinson disease. Arch Neurol 69(5): 601-607. 
CC) This work is licensed under Creative

BY DOI:10.19080/PBSIJ.2021.17.555954

\section{Your next submission with Juniper Publishers will reach you the below assets}

- Quality Editorial service

- Swift Peer Review

- Reprints availability

- E-prints Service

- Manuscript Podcast for convenient understanding

- Global attainment for your research

- Manuscript accessibility in different formats

( Pdf, E-pub, Full Text, Audio)

- Unceasing customer service

Track the below URL for one-step submission https://juniperpublishers.com/online-submission.php 